\title{
Knowledge, attitudes and practices on hand hygiene among ICU staff in Anuradhapura Teaching hospital
}

\author{
BP Kudavidnange ${ }^{1}$, T DCP Gunasekara ${ }^{2}$, S Hapuarachchi ${ }^{3}$ \\ ${ }^{1}$ Anuradhapura teaching hospital. 'Department of Microbilogy, \\ University of Sri Jayawardenepura. ${ }^{3}$ National Hospital of Sri Lanka.
}

\begin{abstract}
Introduction : Hand hygiene practices of health care workers has been shown to be an effective measure in preventing hospital acquired infections.
\end{abstract}

Methodology : We carried out a study to assess the knowledge, attitudes, practices and satisfaction of facilities available to health care workers in the intensive care units with regard to hand hygiene in the Anuradhapura Teaching hospital using a self administered questionnaire.

Results : Our study showed that majority of respondents (72.5\%) had moderate knowledge of hand hygiene. Knowledge on the correct use of hand washing and alcohol hand rubs was not consistent. When the attitudes were assessed for each individual respondents $47.5 \%$ had good attitudes where as a majority (62.5\%) was seen to have poor hand hygiene practices. The level of satisfaction among the health care workers regarding the facilities available for hand hygiene was poor $(55 \%)$.

Conclusion: Hand hygiene knowledge attitudes and practices among ICU staff in Anuradhapura Teaching hospital was moderate to poor. Our study highlights the urgent need for introducing measures to increase the knowledge, attitudes, practices and facilities available for hand hygiene in the ICUs in Anuradhapura Teaching Hospital, which may play a very important role in increasing hand hygiene compliance among the ICU staff and reducing cross transmission of infections among the ICU patients.

\section{Introduction}

Hospital acquired infections (HAls) are infections acquired in hospital by a patient who was admitted for a reason other than that infection. HAls are one of the important public health problems in many countries throughout the world. A WHO study, have also shown that the highest prevalence of nosocomial infections occurs in intensive care units and in acute surgical and orthopaedic wards ${ }^{2}$.

HAls results in higher morbidity, mortality, and additional costs. It is well recognized that the risk of transmission of pathogens when providing medical care and the incidence of HAls can be kept low through appropriate standardized prevention procedures. However, it has been well documented that the level of compliance with the use of proven HAl measures by healthcare workers (HCWs) has been disappointing ${ }^{3}$. In order to overcome this problem it is vital to implement and practice prevention and control strategies with demonstrated value consistently and rigorously. Among the different strategies, the adherence to guidelines for disinfection is an essential ingredient for activities aimed at preventing the HAls. 
The importance of hands in the transmission of hospital infections has been well demonstrated ${ }^{4}$, and can be minimized with appropriate hand hygiene ${ }^{5,6,7,8}$. However, compliance with handwashing, is frequently suboptimal. In the Sri Lankan theatre settings a study demonstrated that only $60 \%$ of the doctors performed appropriate hand washing before entering the theatre ${ }^{9}$. Non compliance with hand washing may be due to a variety of reasons, including: lack of appropriate facilities for hand washing, high staff-to-patient ratios, insufficient knowledge and attitudes of the staff, and allergies to hand washing products. Therefore it is important to address these issue in hospital infection control.

The prevalence of HAls are high in intensive care unit due to patient and environmental factors. The patients are critically ill and usually immunocompromised which predispose them to acquire infections more easily. Critically ill patients requiring urgent and emergency interventions in ICU may cause difficulties to the health care workers to engage in recommended hand hygiene practices. There are several guidelines published by both international and local organizations such as $\mathrm{WHO}^{3}, \mathrm{CDC}^{5}$ and the Sri Lankan college of microbiologists ${ }^{10}$ on hand hygiene. It is important to carry out regular training programs and surveys to assess the hand hygiene practices among the health care workers in Sri Lanka, especially in the intensive care units in order to implement infection control measures.

This study is carried out with the objectives of assessing the knowledge, attitudes, practices and satisfaction of facilities available to health care workers in the intensive care units with regard to hand hygiene in the Anuradhapura Teaching hospital.

\section{Method}

\section{Setting and Study population}

The Anuradhapura Teaching Hospital has 4 ICUs which was included in this study. The hospital houses a Surgical, Medical, Paediatric and Neuro ICUs. The ICU staff members include the consultant, medical officers, nursing staff, paramedical technicians and health care assistants. In addition the medical and nursing students visit the ICU during their training. Verbal consent will be obtained from these health care workers who volunteer to participate in the study.

\section{Study design}

This was a cross sectional study of health care workers hand hygiene knowledge, attitudes, practices and satisfaction with the facilities available for hand hygiene. A self administered questionnaire was given to those health care workers in the ICU, who volunteered to participate in the study. Questionaires were collected at the end of their work shift by the investigators.

Ethical clearance for the study was obtained from the Anuradhapura Teaching hospital, where the study was conducted.

\section{Self administered questionnaire}

The questionnaire will consist of five parts; demographic information, assessment of knowledge, attitudes, practices and facilities available for hand hygiene. Knowledge will be assessed using 8 questions which included multiple choice questions with single answers as well as yes (true)/ No (false) answers. Attitudes will be measured using 10 statements and the respondents were given the option to select on a 1 to 7 point scale between strongly agree and strongly disagree, out of which the first two responses are taken as 
positive responses (strongly agree) and the rest taken as negative responses. Similarly practices and satisfaction with facilities available were assessed in the same method.

Overall knowledge attitudes practices and satisfaction with facilities were assessed for each individual using a scoring system (1 for correct knowledge, good attitudes, correct practices, and satisfaction, 0 for incorrect knowledge, poor attitudes, incorrect practices and dissatisfaction with the availability of facilities for hand hygiene). The average of the score for each category (knowledge, attitudes, practices, satisfaction) was used for calculating the percentage of each category: A percentage of $75 \%$ for knowledge, satisfaction with the facilities available or $70 \%$ for attitudes and practices was considered as good, $50 \%$ - 74\% for knowledge and satisfaction of facilities or $50 \%$ - $69 \%$ for attitudes and practices was considerd as moderate while less than $50 \%$ was considered as poor. obtaining the percentage of correct responses for knowledge, good attitudes, and correct practices, and satisfaction with availability of facilities Data was analysed using EXEL software.

\section{Result}

There was a total of 40 volunteers from the NICU $(n=2), \operatorname{PICU}(n=9), \operatorname{MICU}(n=11)$ and SICU $(n=18)$ of Anuradhapura Teaching Hospital. Of these respondents 8 (20\%) were doctors while 30 (75\%) were nursing staff. Majority of the volunteers were female $(n=31,77.5 \%)$. Most of the participants had 2-5 years work experience (57.5\%). Only $45 \%$ of the study population had received formal training on hand hygiene within the past 3 years while some had never received any formal training. (Table1)

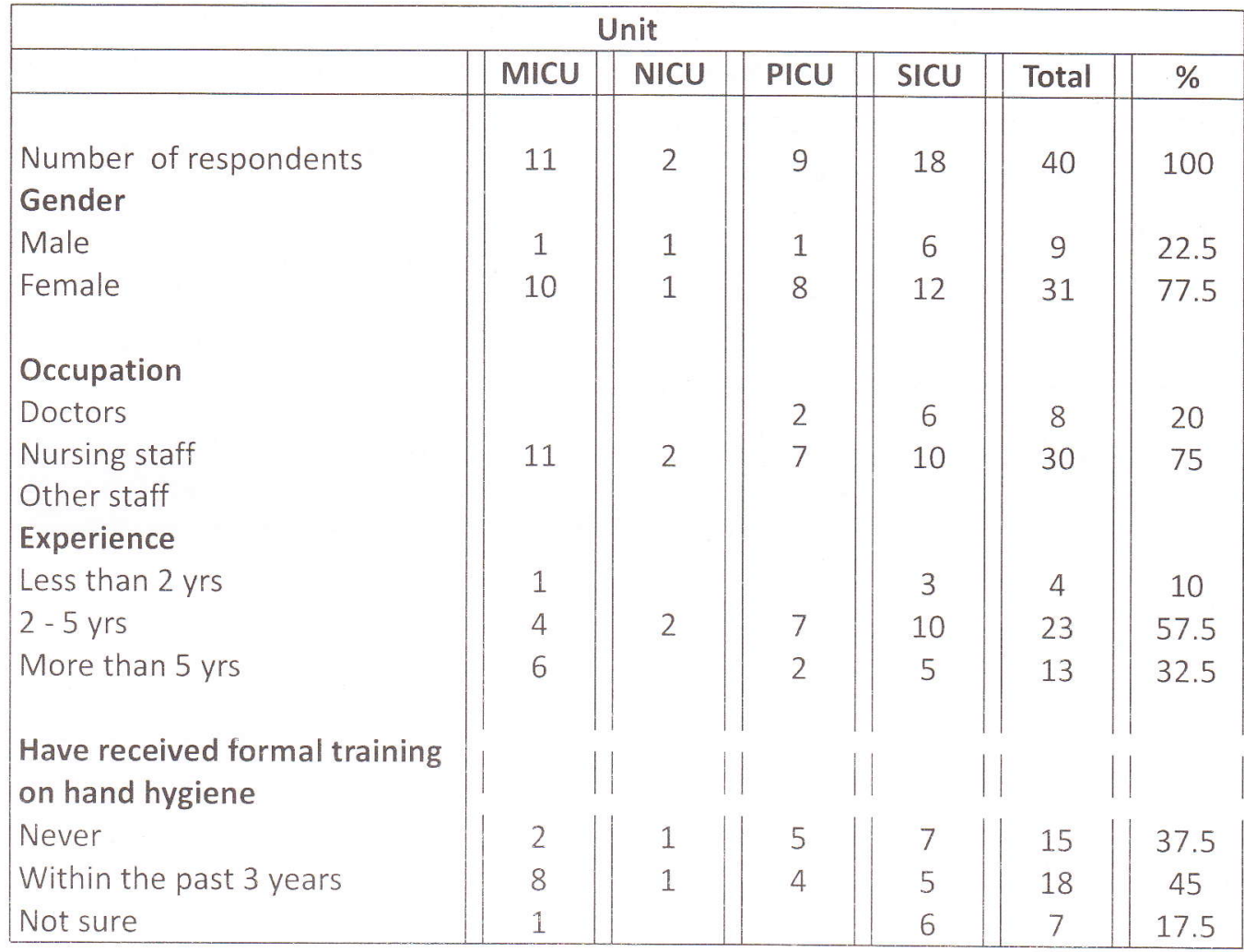

Table 1. Demographic information 
Knowledge on hand hygiene

Our study showed that a majority of the respondents

$(72.5 \% \mathrm{n}=29)$ had moderate knowledge, 9 respondents
(22.5\%) had good knowledge on hand hygiene. while $5 \%$ had poor knowledge. (Table2)

\begin{tabular}{|l|r|r|r|}
\hline & \multicolumn{1}{|c|}{$\begin{array}{r}\text { Good } \\
(\%)\end{array}$} & $\begin{array}{r}\text { Moderate } \\
(\%)\end{array}$ & \multicolumn{1}{c|}{ Poor } \\
\hline Knowledge & 22.5 & 72.5 & 5 \\
Attitudes & 47.5 & 42.5 & 10 \\
Practices & 10 & 27.5 & 62.5 \\
Satisfaction with facilities & 17.5 & 27.5 & 55 \\
\hline
\end{tabular}

Table 2.Analysis of individual respondents knowledge attitudes practices and satisfaction with facilities available for hand hygiene

Many respondents (92.5\%) recognized the importance of health workers hands as a route of cross transmission of harmful germs. While $85 \%(n=34)$ said that hand hygiene before a clean aseptic procedure prevents transmission of germs, all agreed (100\%) that hand hygiene before touching a patient was required to prevent cross transmission of germs to patients. 90\% were knowledgable on the importance of hand hygiene after immediate risk of body fluid exposure. However interestingly $70 \%$ said that the most frequent source of germs responsible for health care associated infections came from the hospital environment while only $25 \%$ knew that germs present on the patient was the main source of infection.

More than $70 \%$ of the respondents had correct knowledge on actions to prevent transmission of germs to the health care worker. However $55 \%$ still thought that hand washing immediately before a clean/aseptic procedure was important in preventing transmission of germs to the health care worker.

Knowledge on the correct use of hand washing and alcohol hand rubs was not consistant. While majority $(80 \%)$ correctly said that hand rubbing was more rapid than washing, they believed it causes skin dryness (55\%), and that rubbing should be followed by hand washing in routine practice(60\%). Only $35 \%$ knew that hand rubbing for 20 seconds was recommended to remove most germs from their hands. From our study the respondents had poor knowledge on the situations where hand rubbing can be used as an alternative to hand washing. However the knowledge on the factors that contribute to hand colonization was good as more than $90 \%$ respondents said that wearing jewellery, damaged skin, artificial fingernails should be avoided. (Table 3 )

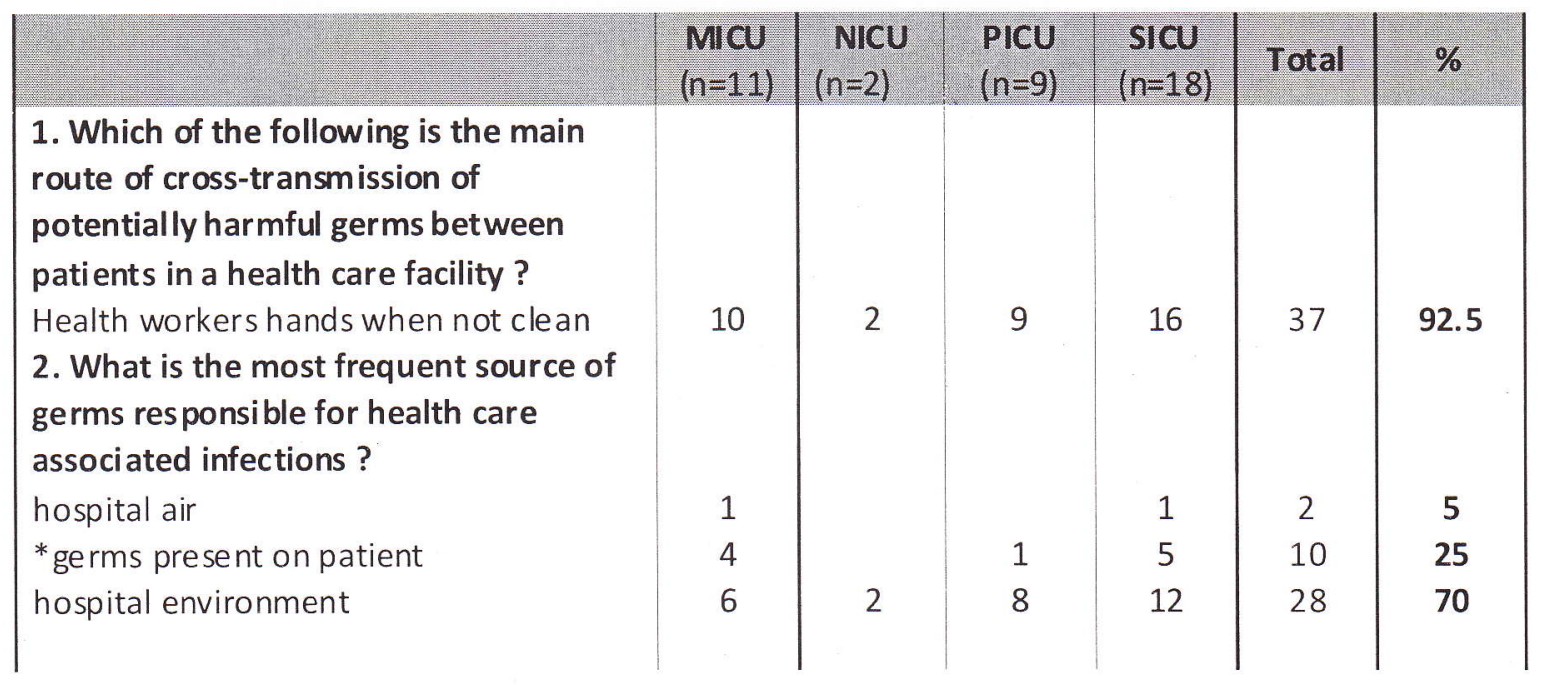




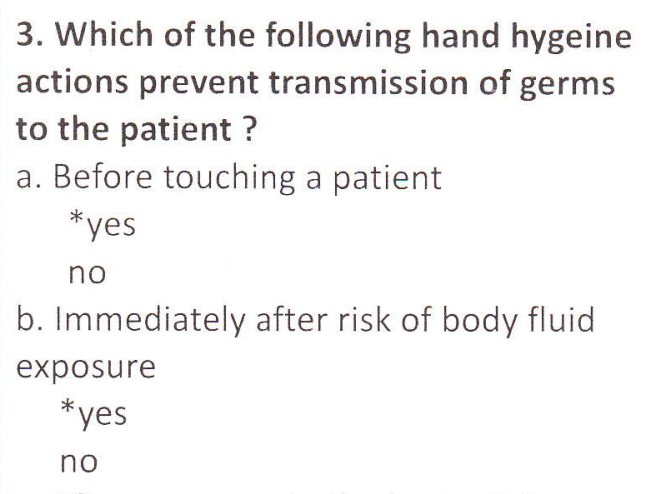

c. After exposure to the immediate surroundings of a patient

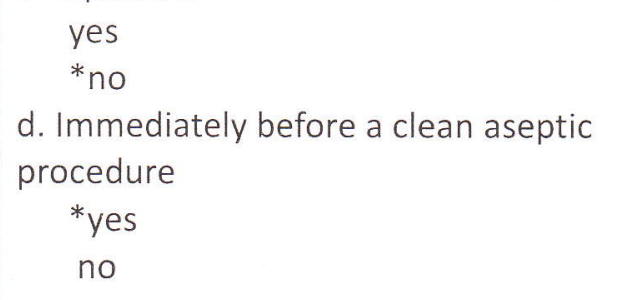

4. Which of the following hand hygeine actions prevents transmission of germs to the health care worker?
a. After touching a patient
*yes
no

b. Immediately after a risk of body fluid exposure

*yes

no
c. Immediately before a clean/aseptic precedure
yes
*no

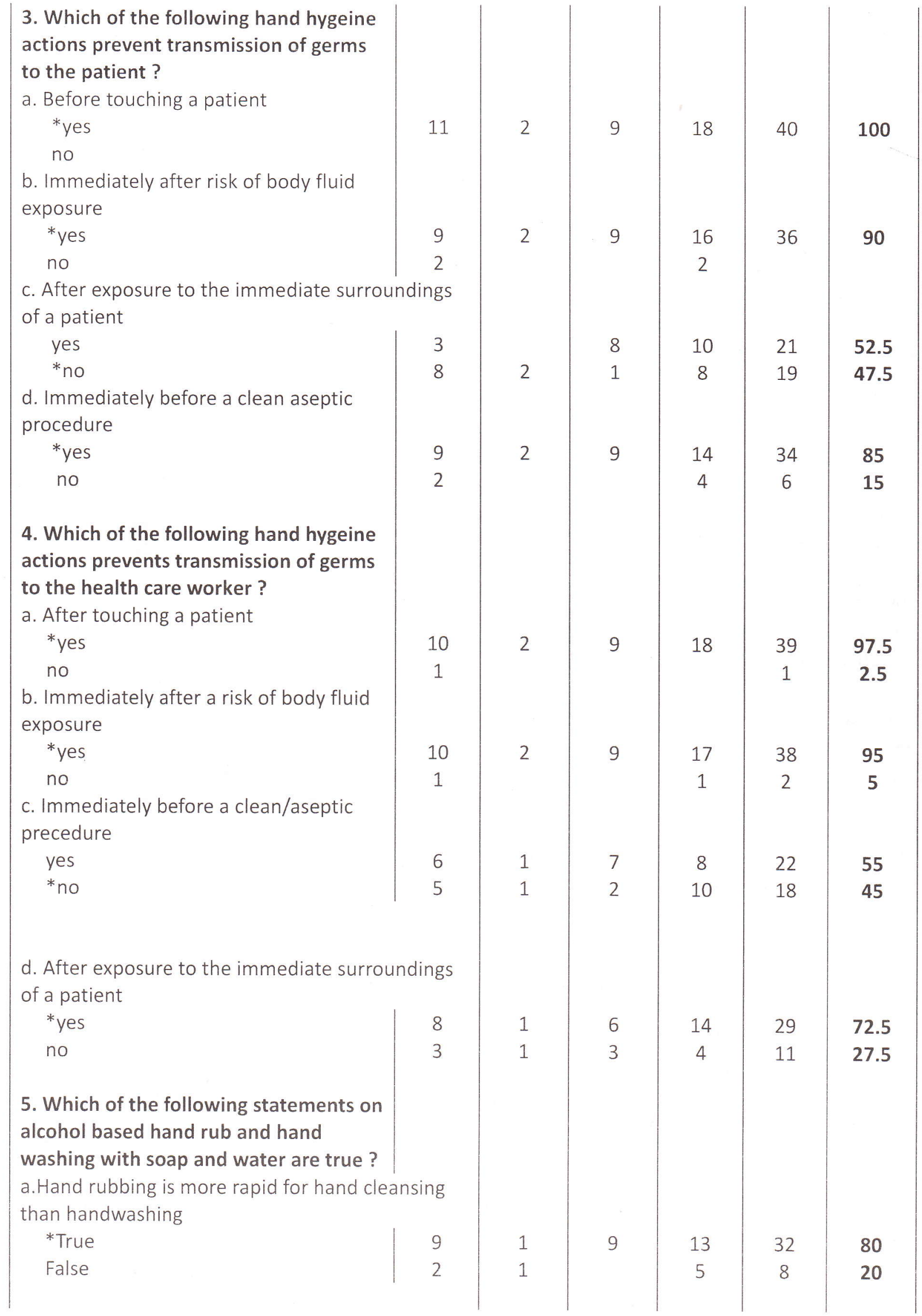




\begin{tabular}{|c|c|c|c|c|c|c|}
\hline \multicolumn{7}{|c|}{$\begin{array}{l}\text { b. Hand rubbing causes skin dryness more than } \\
\text { hand washing }\end{array}$} \\
\hline True & 8 & 2 & 4 & 8 & 22 & 55 \\
\hline *False & 3 & & 5 & 10 & 18 & 45 \\
\hline \multicolumn{7}{|c|}{$\begin{array}{l}\text { c. Handrubbing is more effective against germs } \\
\text { than hand washing }\end{array}$} \\
\hline True & 5 & 2 & 0 & 4 & 11 & 27.5 \\
\hline *False & 6 & & 9 & 14 & 29 & 72.5 \\
\hline $\begin{array}{l}\text { d. Hand washing and hand rubbing are } \\
\text { recommended to be performed in } \\
\text { sequence }\end{array}$ & & & & & & \\
\hline True & 9 & 1 & 4 & 10 & 24 & 60 \\
\hline *False & 2 & 1 & 5 & 8 & 16 & 40 \\
\hline \multicolumn{7}{|l|}{$\begin{array}{l}\text { 6. What is the minimal time needed for } \\
\text { alcohol based hand rub to kill most } \\
\text { germs on your hands? }\end{array}$} \\
\hline *20seconds & 5 & & & 9 & 14 & 35 \\
\hline Others & 6 & 2 & 9 & 9 & 26 & 65 \\
\hline \multicolumn{7}{|l|}{$\begin{array}{l}\text { 7. Which type of hand hygeine method } \\
\text { is required in the following situations? } \\
\text { a. Before palpation of the abdomen }\end{array}$} \\
\hline *rubbing & 5 & & 8 & 13 & 26 & 65 \\
\hline washing & 5 & 1 & 1 & 5 & 12 & 30 \\
\hline \multicolumn{7}{|l|}{ b. Before giving an injection } \\
\hline *rubbing & 4 & 1 & & 1 & 6 & 15 \\
\hline washing & 6 & & 9 & 17 & 32 & 80 \\
\hline \multicolumn{7}{|l|}{ c. after emptying a bed pan } \\
\hline rubbing & 2 & & & 3 & 5 & 12.5 \\
\hline *washing & 8 & 1 & 9 & 15 & 33 & 82.5 \\
\hline \multicolumn{7}{|l|}{ d. After removing examination gloves } \\
\hline *rubbing & 4 & & & 4 & 8 & 20 \\
\hline *washing & 6 & 1 & 8 & 11 & 26 & 65 \\
\hline e. after making a patients bed & 2 & & & 2 & 2 & 5 \\
\hline washing & 8 & 1 & 9 & 15 & 33 & 82.5 \\
\hline f. after visible exposure to blood & & & & & & \\
\hline rubbing & 5 & 1 & & 3 & 9 & 22.5 \\
\hline *washing & 5 & & 9 & 14 & 28 & 70 \\
\hline
\end{tabular}




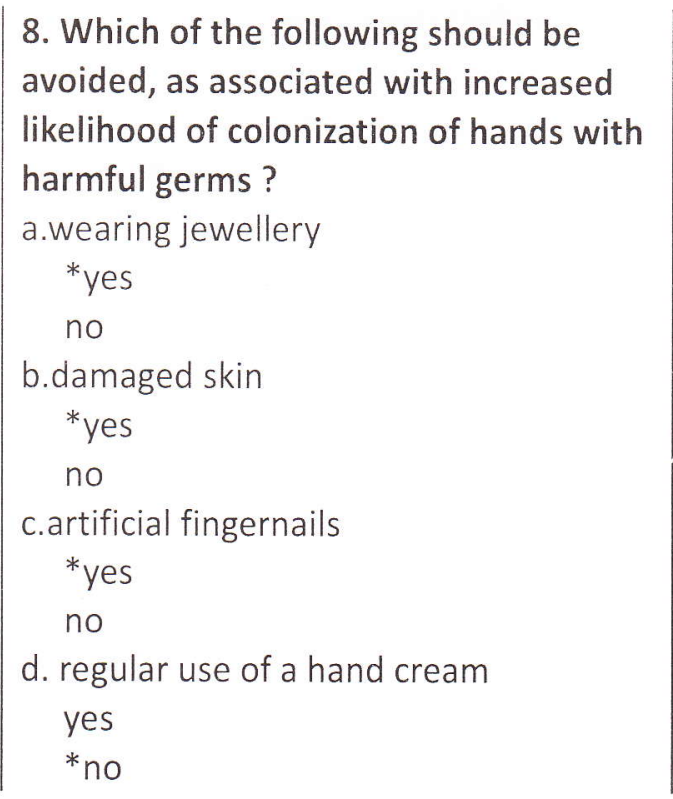

\begin{tabular}{|c|c|c|c|c|c|} 
& & & & \\
& & & & & \\
10 & & & & & \\
1 & & & & & \\
1 & 1 & & 16 & 36 & 90 \\
1 & 1 & & 2 & 4 & 10 \\
10 & 1 & & 16 & 36 & 90 \\
1 & 1 & 9 & 17 & 37 & 92.5 \\
3 & 1 & & 1 & 3 & 7.5 \\
8 & 1 & 7 & 11 & 27 & 67.5
\end{tabular}

\section{* correct response}

Table 3. Knowledge on hand hygiene

\section{Attitudes on hand hygiene}

When the attitudes were assessed for each individual respondents $47.5 \%$ had good attitudes while $42.5 \%$ had moderate attitudes. Ten percent showed poor attitudes.

Only $40 \%$ agreed that they adhered to correct hand hygiene practices at all times. $42.5 \%$ said that emergencies and other priorities made hand hygiene more difficult. $60 \%$ said that they felt guilty if they omitted hand hygiene. More than 75\% disagreed that they miss out hand hygiene as they forget it or because they have more important things to. Regarding the attitude towards others hand hygiene, $62.5 \%$ disagreed that they felt frustrated when others omit hand hygeien, and $75 \%$ disagreed that they are reluctant to ask others to engage in hand hygiene. Only 35\% were of the attitude that newly qualified staff were not properly instructed on hand hygiene methods. Half of the respondents believed that adhering to hand hygiene practices is easy in the current ICU setup. (Table 4) 


\begin{tabular}{|c|c|c|c|c|c|c|}
\hline 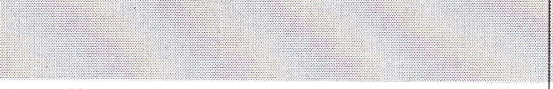 & $\begin{array}{l}\text { MICU } \\
(n=11)\end{array}$ & $\begin{array}{l}\text { NICU } \\
(n=2)\end{array}$ & $\begin{array}{l}\text { PICU } \\
(n=9)\end{array}$ & $\begin{array}{l}\text { SICU } \\
(n=18)\end{array}$ & Total & $\%$ \\
\hline \multicolumn{7}{|l|}{$\begin{array}{l}9.1 \text { adhere to correct hand hygiene } \\
\text { practices at all times }\end{array}$} \\
\hline Agree & 8 & & 1 & 7 & 16 & 40 \\
\hline Disagree & 3 & 2 & 8 & 11 & 24 & 60 \\
\hline \multicolumn{7}{|l|}{$\begin{array}{l}\text { 10. Sometimes I have more things to do } \\
\text { than hand hygiene }\end{array}$} \\
\hline Agree & 5 & & & 5 & 10 & 25 \\
\hline Disagree & 6 & 2 & 9 & 13 & 30 & 75 \\
\hline \multicolumn{7}{|l|}{$\begin{array}{l}\text { 11. Sometimes I miss out hand hygiene } \\
\text { simply because I forget it }\end{array}$} \\
\hline Agree & 2 & & & 3 & 5 & 12.5 \\
\hline Disagree & 9 & 2 & 9 & 15 & 35 & 87.5 \\
\hline \multicolumn{7}{|l|}{$\begin{array}{l}\text { 12.Emergencies and other priorities } \\
\text { make hygiene more difficult at times }\end{array}$} \\
\hline Agree & 5 & & 4 & 8 & 17 & 42.5 \\
\hline Disagree & 6 & 2 & 5 & 10 & 23 & 57.5 \\
\hline \multicolumn{7}{|l|}{$\begin{array}{l}\text { 13. Wearing gloves reduce the need for } \\
\text { hand hygiene }\end{array}$} \\
\hline Agree & 1 & & 1 & 3 & 5 & 12.5 \\
\hline Disagree & 10 & 2 & 8 & 15 & 35 & 87.5 \\
\hline \multicolumn{7}{|l|}{$\begin{array}{l}\text { 14.I feel frustrated when others omit } \\
\text { hand hygiene }\end{array}$} \\
\hline Agree & 4 & & 4 & 7 & 15 & 37.5 \\
\hline Disagree & 7 & 2 & 5 & 11 & 25 & 62.5 \\
\hline \multicolumn{7}{|l|}{$\begin{array}{l}\text { 15.I am reluctant to ask others to engage } \\
\text { in hand hygiene }\end{array}$} \\
\hline Agree & 1 & & 2 & 7 & 10 & 25 \\
\hline Disagree & 10 & 2 & 7 & 11 & 30 & 75 \\
\hline \multicolumn{7}{|l|}{$\begin{array}{l}\text { 16. newly qualified staff has not been } \\
\text { properly instructed in hand hygiene } \\
\text { in their training }\end{array}$} \\
\hline Agree & 4 & & 4 & 6 & 14 & 35 \\
\hline Disagree & 7 & 2 & 5 & 12 & 26 & 65 \\
\hline \multicolumn{7}{|l|}{ 17.I feel guilty I omit hand hygiene } \\
\hline Agree & 5 & & 4 & 15 & 24 & 60 \\
\hline Disagree & 6 & 2 & 5 & 3 & 16 & 40 \\
\hline \multicolumn{7}{|l|}{$\begin{array}{l}\text { 18. Adhering to hand hygiene practices is } \\
\text { easy in the current ICU setup }\end{array}$} \\
\hline Agree & 6 & 2 & 1 & 11 & 20 & 50 \\
\hline Disagree & 5 & & 8 & 7 & 20 & 50 \\
\hline
\end{tabular}

Table 4. Attitudes towards hand hygiene

\section{Practices on hand hygiene}

Regarding the practices on hand hygiene, when the individual responses were assessed for practices, $10 \%$ had overall good practices, while $27.5 \%$ had moderate practices. However majority (62.5\%) was seen to have poor hand hygiene practices.
However $60 \%$ claimed that they had sufficient knowledge about hand hygiene. Half of the respondents said that they practiced hand hygiene as a non negotiable part of his/her role. Majority of respondents (57.5\%) said that there were no adverts regarding hand hygiene in their work place. 
Surprisingly $82.5 \%$ said that the frequency of hand hygiene required was not difficult to achieve. However $67.5 \%$ felt that the facilities for hand hygiene in their work place was adequate. The influence towards hand hygiene by the infection prevention team or infection prevention notices was low. (32.5\%, 47.5\%). (Table 5)

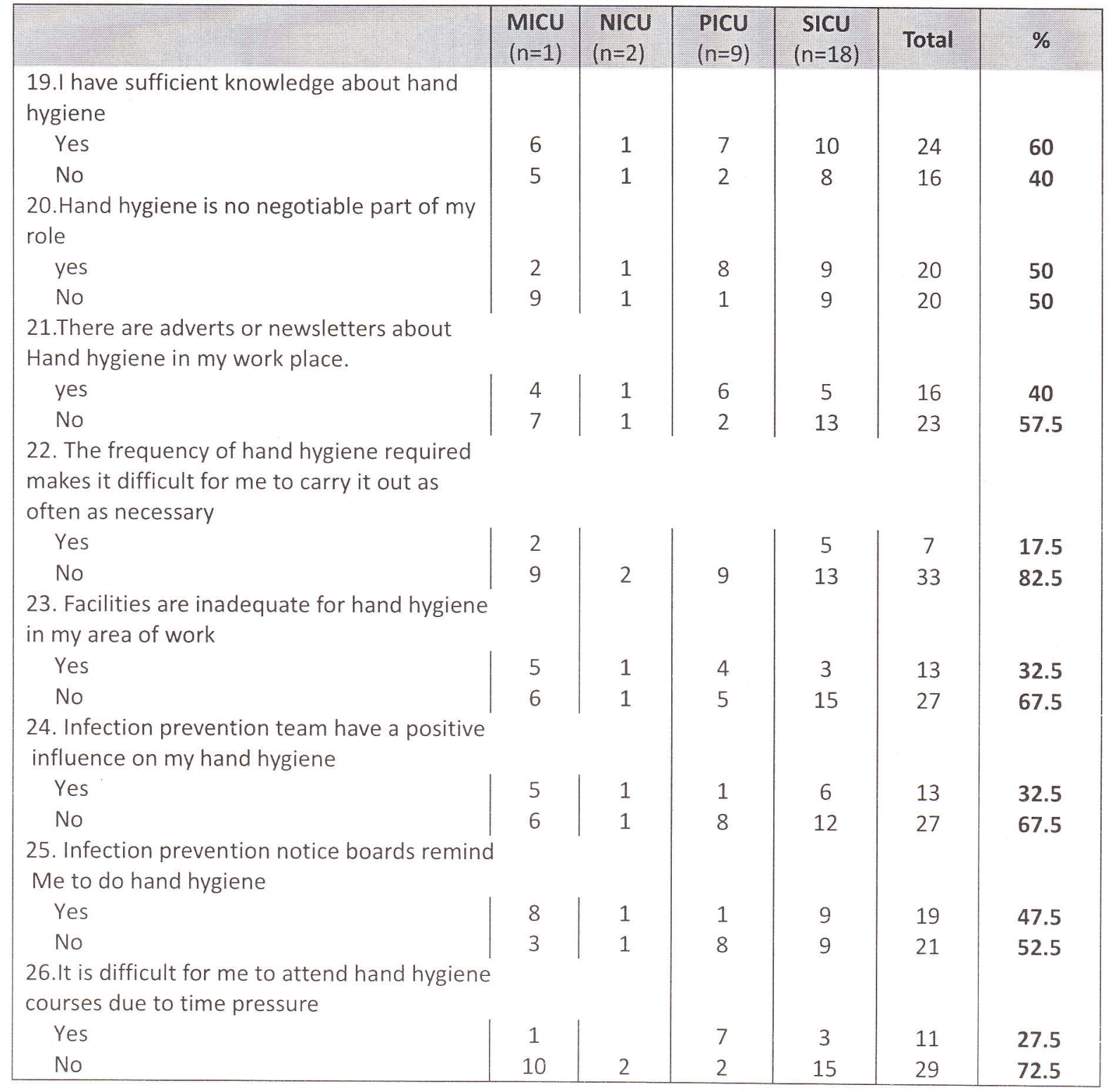

Table 5. Practices regarding Hand hygiene

Satisfaction regarding the facilities available for hand hygiene

The satisfaction of the volunteer health care workers regarding the facilities available for hand hygiene was poor (55\%). Only $17.5 \%$ felt that the facilities were sufficient while $27.5 \%$ felt moderately satisfied with the current facilities.

While $65 \%$ were satisfied with the soap/antiseptics and water availability, $75 \%$ were satisfied with the availability of alcohol hand rub. However 
paper/cloth for drying hands and number of sinks with running water were not satisfactory $160 \%$ and $65 \%$ respectively). Majority of the volunteers
$(82.5 \%)$ were not satisfied with the training programmes on hand hygiene available to them (Table 6).

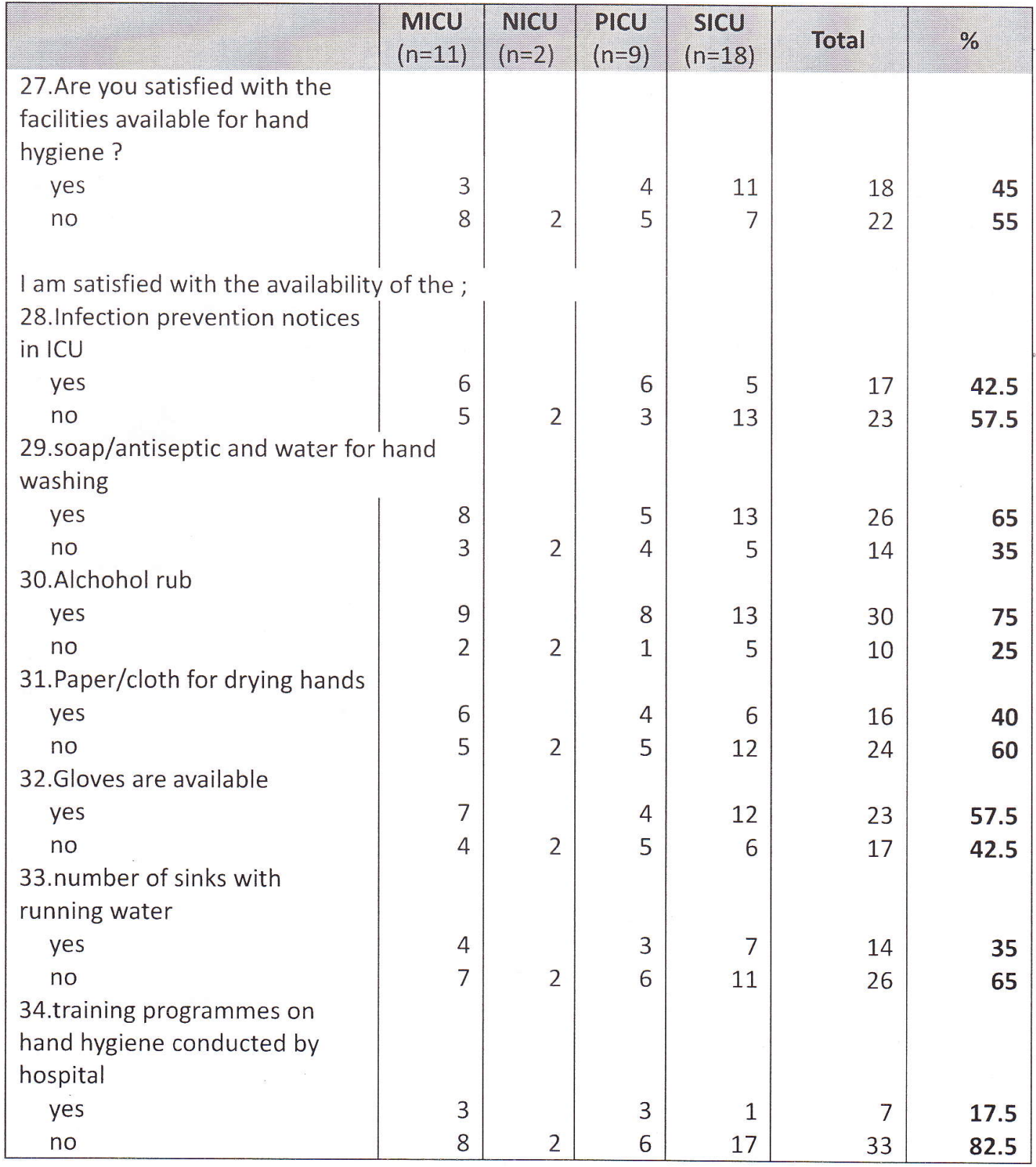

Table 6. Satisfaction regarding facilities available for hand hygiene

\section{Discussion}

Hand hygiene is a simple procedure which is instrumental in reducing hospital acquired infections and cross transmission of pathogens in the hospitals and specially among the ICU patients. The present study shows that majority of the respondents had moderate knowledge, while approximately half of the respondents had good attitudes while majority had poor hand hygiene practices. In addition almost half of the respondents felt that the facilities available for hand hygiene was not adequate. Despite the fact that hand hygiene is 
considered as the single best measure for infection control, compliance of health care workers regarding hand hygiene remains consistently poor ${ }^{11}$.

The present study was conducted to assess the current situation of hand hygiene in the Anuradhapura Teaching hospital and to put forth recommendations to improve hand hygiene measures and thereby reduce the rate of cross transmission of infections in the ICUs. A study has shown that constant motivation through movies, brochures, posters etc. results in transient improvement in hand hygiene ${ }^{12}$. Our results suggest that there is wide scope for improvement in hand hygiene practices in the Anuradhapura Teaching hospital ICUs as well as wards. It was interesting to note that less than half of the respondents had received formal training in hand hygiene. This can be addressed by routinely conducting hand hygiene training programmes using the teaching materials from WHO and making the health care workers knowledgeable on hand hygiene guidelines put forth by the WHO. It is also important to encourage the infection control team to play a more active role in hand hygiene awareness and training in the hospitals specially in the ICU setup. They should be encouraged to interact with the staff members and thereby exert a positive influence on their attitudes and practices regarding hand hygiene. The current ICUs do not have displays of infection prevention notices/ five moments of hand hygiene. Therefore it is possible that by introducing these notices to the ICUs it is possible to increase hand hygiene knowledge and compliance among the attending staff members.

It was interesting to note that although hand rub was satisfactorily available the respondents were not aware of the situations that hand rub can be used in place of hand washing. As hand washing takes up about one minute and requires a sink with running water, soap/ antiseptic as compared to hand rubbing which takes only 20 seconds, it is important to make the health care workers knowledgeable on the appropriate use of hand rubbing and to encourage its use further to improve compliance.

Similar to studies reported from other developing countries, the health care workers in our ICUs were not satisfied with the facilities available for hand hygiene. Therefore we need to address this issue and improve facilities such as improving the availability of soap/antiseptics, paper/cloth for drying hands and gloves. Further it is essential to conduct hand hygiene training programmes for the ICU staff members.

Our study has several drawbacks which need to be considered when interpreting this data. Data was collected by using a self administered questionnaire, which allows the respondent to check others responses or discuss the answers as well as document the expected response rather than the health care workers own practice or attitudes. This can be overcome by incorporating an observational study which will enable the investigator to observe the actual hand hygiene practices among these health care workers. However it is not easy to conduct such a study currently due to the high work load and time restrains.

In conclusion our study highlights the urgent need for introducing measures inorder to increase the knowledge, attitudes, practices and facilities available for hand hygiene in the ICUs in Anuradhapura Teaching Hospital, which may play a very important role in increasing hand hygiene compliance among the ICU staff and reducing cross transmission of infections among the ICU patients. 


\section{Acknowledgements}

I acknowledge the contributions made by $\mathrm{Mr}$. Bandara, Master in charge of SICU, Anuradhapura

\section{References}

1. World Health Organization.(2001) WHO Global Strategy for Containment of Antimicrobial Resistance. WHO/CDS/CSR/DRS/2001.2.

2. World Health Organization. Prevention of hospital acquired infections. A practical guide. Edited by Ducell, G, Fabry J, Nicoll L. 2002

3. World Health Organization.(2009) WHO Guidelines on Hand Hygiene in Health Care: First global safety challenge: clean care is safe care. Geneva:WHO[http://whqlibdoc.who.int/public ations/2009/9789241597906_eng.pdf], Accessed June 18, 2010.

4. Larson E. A causelink between handwashing and risk of infection? Examination of the evidence.Infect Control Hosp Epidemiol, 1988, 9:28-36.

5. CDC (1986) Guidelines for handwashing and hospital environmental control. Amer J infect Control, 110-129 or Infect Control, 1986, 7:231-242.

6. Larson EL. (1995) APIC guideline for handwashing and hand antisepsis in health care settings. Amer J Infect Control, 23:251-269.

7. Health Canada. (1998) Hand washing, cleaning, disinfection, and sterilization in health care.
Teaching Hospital and other staff members who volunteered to participate in the study.

Canada Communicable Disease Report (CCDR), Supplement, Vol., 24S4

8. Dabare GMI, Dissanayake DMBT, Weerasekara D, Mahendra R, Fernandon N. (2004) The efficacy of surgical scrubs in reducing hand bacterial flora. The Ceylon journal of medial sciences. 47:1-6

9. T. D.C. P. Gunasekara, B. P. Kudavidanage, M.K. Peelawattage, F. Meedin,L. D. Guruge, G. Nanayakkara,M. Nanayakkara,S.S.N. Fernando. (2009) Bacterial contamination of anaesthetsts hands, personal mobile phones and wrist watches used during theatre sessions. Sri Lankan Journal of Anaesthesiology 17(1) : $11-15$

10. Sri Lankan college of microbiologists.

11. Anwar M.A., Rabbi, S., Masroor M., Majeed F., Andrades M., Baqi s.(2009) Self-reported practices of hand hygiene among the trainees of a teaching hospital in a resource limited country. Journal of Pakistan Medical Association. 59(9):631-634

12. Rao, M. H. (2006) Knowledge, attitude and practice patterns of hand washing in major public sector hospitals of Karachi. Pakistan Journal of Medical Research. 45(4)

\section{Authors}

- BP. Kudavidnange

Acting Consultant Anaesthetist, Anuradhapura teaching hospital

- TDCP Gunasekara

Senior Lecturer, Department of Microbilogy University of Sri Jayawardenepura

- S Hapuarachchi

Consultant Anaesthetist, NHSL 